\title{
Olive stone: a source of energy generation and a suitable precursor for activated carbon production
}

\author{
S. Román ${ }^{1}$, J. F. González ${ }^{1}$, J. M. Encinar ${ }^{2}$ \\ ${ }^{1}$ Department of Applied Physics. ${ }^{2}$ Department of Chemical Engineering and Physical Chemistry. \\ Extremadura University, Avenida de Elvas s/n, 06078 Badajoz (Spain) \\ Phone/Fax number: +0034 924 289619, e-mail: ifelixgg@unex.es
}

\begin{abstract}
This work is focussed on the study of the reactions involved in the process of steam and $\mathrm{CO}_{2}$ gasification of olive stone char, in order to optimize both the energy content in the gas generated and the development of porosity produced in the char.
\end{abstract}

\section{KEY WORDS}

Gasification, biomass, energy, hydrogen, activated carbon, porosity.

\section{INTRODUCTION}

Nowadays, fossil fuels, presently contributing to $80 \%$ of world primary energy, are inflicting enormous impacts on the environment. Moreover, their future exhaustion and the absence of a clear replacement entail a threat for worldwide energy and economic system. A secure and accessible supply of energy is thus very crucial for the sustainability of modern societies. There is an urgent need for a quick switch over of energy systems from conventional to renewable that are sustainable and can meet the present and projected world energy demand.

Biomass has great potential as a clean, renewable feedstock for producing modern energy carriers. Having into account that nowadays biomass represents only $3 \%$ of primary energy consumption in industrialized countries (and according to European Community, its contribution to primary energy in Europe would reach around $9 \%$ by year 2010), is evident that intense research focused on improving biomass conversion into energy has to be done.

Among all the current technologies that convert biomass into gaseous products, biomass gasification is considered as one of the most promising thermochemical technologies and much research on it is being made on both fluidized bed and downdraft gasifiers [1]. Also biomass pyrolysis processes have been proved to be very interesting in order to obtain energetic gaseous products [2-3].

Focussing on the products derived from biomass pyrolysis processes, it is well known that, apart from the gas (mainly composed by $\mathrm{H}_{2}, \mathrm{CO}, \mathrm{CO}_{2}, \mathrm{CH}_{4}$, etc, which could be employed in internal combustion engines, gas turbines and other operating devices) and tars (which have a low HHV); a solid carbonaceous residue (char) is generated. This char is characterized by a high carbon content $(>75 \%)$ and a narrow microporous structure, which makes it suitable to be a good precursor for activated carbon (AC) production by physical activation.

Activated carbons are porous materials that (due to their chemical and textural characteristics) are able to adsorb certain amounts of compounds in the liquid and gaseous phases; this property makes these solids very interesting to be used in many industrial applications. AC production consists, in general terms on the activation (physical or chemical) of a suitable precursor. Chemical activation consists on the impregnation (with different chemicals) of the raw material, followed by a carbonization. Physical activation (the most used one, and the process we used here) consist of the carbonization of the raw material, followed by a thermal treatment of the char with an activating agent (air, steam, $\mathrm{CO}_{2} \ldots$ ). Independently of the activation process employed, the operating parameters (time, temperature, activating agent, chemical product...) will influence the final textural and chemical surface properties of the AC produced.

There is a huge amount of research on the production of $\mathrm{AC}$ from biomass residues but the information about the gases generated in this process is scarce. Considering that, specially when steam is used as activating agent, the gas resulting from the activation has an important content in $\mathrm{H}_{2}, \mathrm{CO}$ and $\mathrm{CH}_{4}$, it could be interesting to study the reactions involved between the carbon of the char and the activating agents employed $\left(\mathrm{CO}_{2}\right.$, steam and a mixture of them). Since both the development of porosity produced in the char and the final gas composition are interdependent, changes on the variables employed (such as activating agent or temperature) will affect them.

The aim of this work is to study the exploitation of olive stones following the next scheme:

- Pyrolysis: energetic study of the gas and liquid phases generated, determining their HHV and proposing some applications for them.

- Gasification of the char, using $\mathrm{CO}_{2}$, steam and a mixture of them, evaluating the composition of the gas generated (and analysing the reactions 
involved) and the textural characteristics of the carbons produced.

Olive stones were chosen as raw material, since they are extensively generated in Europe (the residues generated by the EU olive oil milling industry have been estimated to be 6.8 million tonnes/year) [2].

\section{EXPERIMENTAL SET-UP}

Olive stones were obtained from local olive manufacturers (Finca La Orden, Extremadura) and shredded to 1-1.6 $\mathrm{mm}$. The proximate and ultimate analyses of this raw material are shown in Table 1.

Table 1. Various analyses of olive stone

\begin{tabular}{|c|cccc|c|}
\hline & Carbon & Hydrogen & Nitrogen & Sulphur & Oxygen \\
\hline $\begin{array}{c}\text { Ultimate } \\
\text { analysis }\end{array}$ & 39.43 & 6.23 & 0.71 & 0.03 & 53.6 \\
\hline & Fixed carbon & Moisture & Volatile & Ash & \\
\hline $\begin{array}{c}\text { Proximate } \\
\text { analysis }\end{array}$ & 10.44 & 12.69 & 72.29 & 4.58 & \\
\hline
\end{tabular}

One can see that olive waste has a high content of volatile matter and low content of ash, nitrogen and sulfur, which is interesting with respect to its applications in gasification and pyrolysis processes. The low content of $\mathrm{S}$ diminishes the possibility of acid species formation which can produce "acid rain" or corrode the metallic parts of the gasification installation. The low $\mathrm{N}$ content ensures that thermal $\mathrm{NO}_{\mathrm{x}}$ formation during the gasification process is negligible.

The procedure followed to carry out the experiments and the experimental installation used in both pyrolysis and activation processes has been described in detail elsewhere [4] and is shown in Figure 1. The numbers describing each part of this installation mean: 1-2: gases used; 3: distilled water which will pass through a coil inserted in furnace (5-6) to be vaporized; 7-8: pyrolysis or gasification reactor inserted in an electrical furnace; 9: tar collecting system (covered by ice); 10: gas samples collecting system; 11-12: flowmeter.

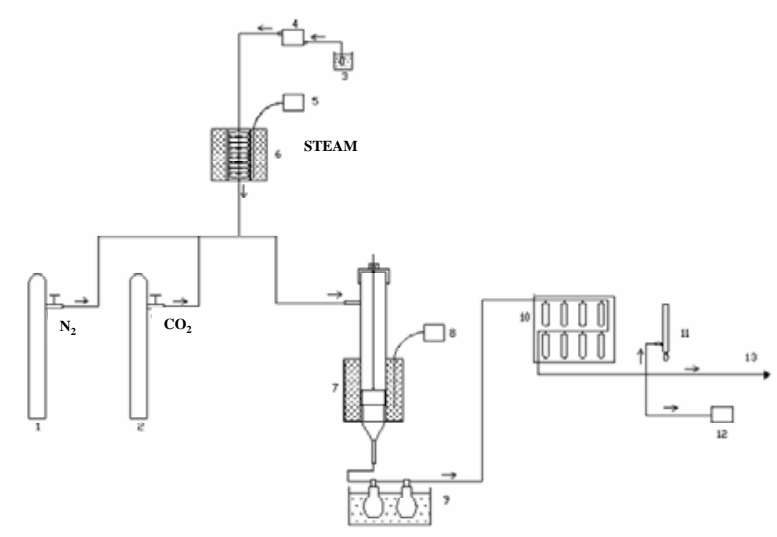

Figure 1. Experimental set-up.
Carbonization processes were conducted with $\mathrm{N}_{2}(150$ $\left.\mathrm{mL} \cdot \min ^{-1}\right)$, during $1 \mathrm{~h}$. In activation processes, $\mathrm{N}_{2}(80 \mathrm{~mL}$ $\min ^{-1}$ ) was fed during the heating and cooling steps, so that oxygen from the air does not burn off the sample. Once the conditions were attained, the gasyfing agent was made to pass through the gasifier: $\mathrm{CO}_{2}(40 \mathrm{~mL} \mathrm{~min}$ ${ }^{1}$ ), water steam (with a flow of $0.41 \mathrm{~g} \mathrm{~min}^{-1}$, diluted in the $\mathrm{N}_{2}$ flow) and mixtures $\mathrm{CO}_{2}$ plus steam (in this case 0,41 $\mathrm{mL} \mathrm{m^{-1 }}$ of steam were used and $\mathrm{CO}_{2}\left(40 \mathrm{~mL} \mathrm{~min}^{-1}\right)$ was used as carrier agent). The activation time used in all the experiments was equal to 20 minutes.

The gas produced was made to pass through a quenching system (glass recipients covered by ice), where the tars and condensable liquids were collected. Next, the gas flow rate was measured with a flowmeter. The composition of the gas produced; mainly $\mathrm{H}_{2}, \mathrm{CO}$, $\mathrm{CO}_{2}, \mathrm{CH}_{4}$, and $\mathrm{O}_{2}$ (and small traces of $\mathrm{C}_{2} \mathrm{H}_{2}, \mathrm{C}_{2} \mathrm{H}_{4}$ and $\mathrm{C}_{2} \mathrm{H}_{6}$ ), was analysed by a 4000 HRGC KONIK gas chromatograph provided with two thermal conductivity detectors, connected to two columns: Porapack Q and Carboxen-1000 (15 ft length, 1/8 inch diameter).

The higher heating value (HHV) of the tar generated in the pyrolytic process was determined with a Parr 1351 calorimeter bomb (norm ISO 1928).

The activated carbons were characterized by adsorption of $\mathrm{N}_{2}$ at $77 \mathrm{~K}$ (AUTOSORB-1, Quantachrome). The olive stone char was also characterized by adsorption of $\mathrm{CO}_{2}$ a $273 \mathrm{~K}$, using a volumetric manual system.

\section{Calculation of textural characterization of carbons:}

From the $\mathrm{N}_{2}$ adsorption isotherms at $77 \mathrm{~K}$, the specific surface area was estimated by two methods: firstly by applying the Brunauer, Emmett and Teller (BET) equation [5] for calculating the $\mathrm{S}_{\mathrm{BET}}$ values, and secondly by estimating the statistical thickness of the adsorbed layer $(\mathrm{t})$ by applying the $\mathrm{t}$ method [6] for the calculation of the external surface $\left(\mathrm{S}_{\mathrm{ex}}\right)$ and micropore volume $\left(\mathrm{V}_{\mathrm{mi}(\mathrm{t})}\right)$. A non-porous activated carbon made from olive stones by Rodríguez-Reinoso et al. [7] was used as reference material. The $t$ values used in the least square analysis ranged between 3.5 and 5, which corresponds to $\mathrm{P} / \mathrm{P}_{0}$ values varying between about 0.07 and 0.3 . Moreover, the volumes of micro and mesopores were also calculated according to Gurvitch's rule (named as $\mathrm{V}_{\mathrm{miG}}$ and $\mathrm{V}_{\mathrm{meG}}$ ).

In the case of the char, since it may possess a very narrow and incipient microporosity (which cannot be measured with $77 \mathrm{~K}$ nitrogen adsorption due to the negligible adsorption kinetics at this temperature), carbon dioxide adsorption at $273 \mathrm{~K}$ was used to evaluate its micropore volume by applying Dubinin-Radushkevich equation [8]:

$$
\log \mathrm{V}=\log \mathrm{V}_{0}-\operatorname{Dlog}^{2}\left(\mathrm{P}_{0} / \mathrm{P}\right)
$$

\section{DISCUSSION OF RESULTS}

The pyrolytic process resulted in a solid yield equal to $21.8 \%$. This value is associated with the removal of moisture and volatile compounds (which compose more 
than $80 \%$ of its weight). The molar concentrations of the main components $\left(\mathrm{H}_{2}, \mathrm{CO}, \mathrm{CH}_{4}, \mathrm{CO}_{2}\right)$ generated during the pyrolytic process along the reaction time have been plotted in Figure 2. One can see that the maximun concentration is attained for all these molecules at about 3 minutes. The molar fractions of the whole gas generated are 0,$228 ; 0,131 ; 0,074$ and 0,213 for $\mathrm{H}_{2}, \mathrm{CO}$, $\mathrm{CH}_{4}$ and $\mathrm{CO}_{2}$ respectively (the remaining is $\mathrm{N}_{2}$ and $\mathrm{O}_{2}$ ).

This composition confers this gas a HHV equal to 7,52 $\mathrm{MJ} \mathrm{Nm}^{-3}$, which makes it suitable to be used to confer part of the heat needed for the subsequent activation processes (also to vaporize the water steam used in further activation of the char).

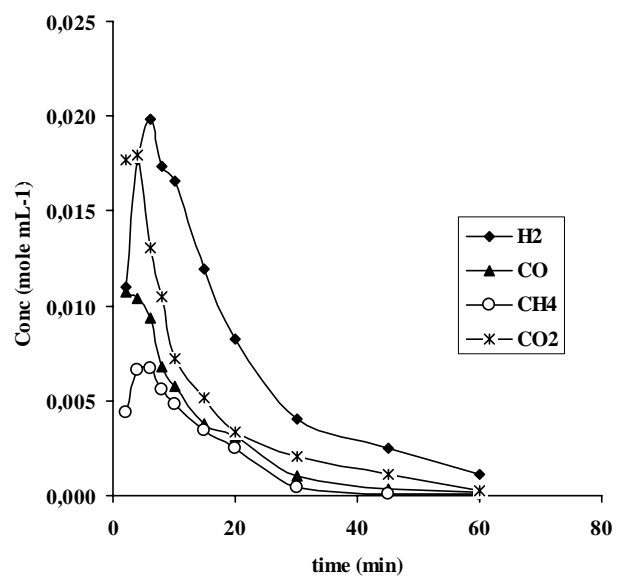

Figure 2. Gases produced during olive stone carbonization

The HHV of the tar generated is $11.6 \mathrm{MJ} \mathrm{kg}^{-1}$. The applications associated to this low-medium HHV could be as fuel in boiler, gas turbines or diesel engines, as it has already been reported by some authors [9]. However, we think that the most recommendable is to try to favour the cracking of these tars, since they mean a very important obstacle in the refrigeration and cleaning system of the gas used to generate electric power. Apart from that, tar cracking could result in an increase of the energy content of the gas. Future works made by this group will be made with the aim of studying tars removal by means of thermal and catalytic cracking.

Focussing on its potential as a precursor for $\mathrm{AC}$ production, the char possesses a porous structure that is scarcely developed $\left(\mathrm{S}_{\mathrm{BET}}=43 \mathrm{~m}^{2} \mathrm{~g}^{-1}\right)$. The different value for micropore volume calculated from $\mathrm{N}_{2}$ adsorption at $77 \mathrm{~K}\left(\mathrm{~V}_{\mathrm{mi}}=0.02 \mathrm{~cm}^{3} \mathrm{~g}^{-1}\right)$ and $\mathrm{CO}_{2}$ adsorption a $273 \mathrm{~K}\left(0.41 \mathrm{~cm}^{3} \mathrm{~g}^{-1}\right)$ demonstrates that this char might possess narrow constrictions, which difficulty the access of $\mathrm{N}_{2}$ molecule at $77 \mathrm{~K}$. This char is therefore composed by very narrow pores as a result of the deposition of tars and volatile matter which were released during the carbonization process and partially blocks the carbon porous structure.

The activation of this char was studied in the range of temperature $800-900^{\circ} \mathrm{C}$ for steam. The effect of the activating agent was studied at $850^{\circ} \mathrm{C}$, making activations with steam, $\mathrm{CO}_{2}$ and $\mathrm{CO}_{2}+$ steam at $850^{\circ} \mathrm{C}$. Table 2 shows the molar fractions, $\mathrm{H}_{2}$ production and $\mathrm{HHV}$ of the gases produced in these processes (in these tables the nomenclature used was: $\mathrm{S}$ : steam, CS: carbon dioxide+steam, $\mathrm{C}$ : carbon dioxide). The textural characteristics of the activated carbons produced have been collected in Table 3 .

We will analyse the composition of the gas generated in the different gasification processes first. Steam gasification results in the participation of several equilibria from which the following reactions are the most important:

Water gas reaction

(1) $\mathrm{C}+\mathrm{H}_{2} \mathrm{O} \rightarrow \mathrm{CO}+\mathrm{H}_{2} \quad \Delta \mathrm{H}=118.9 \mathrm{kJmol}^{-1}$

Hydrogasification reaction

(2) $\mathrm{C}+2 \mathrm{H}_{2} \rightarrow \mathrm{CH}_{4}$

$\Delta \mathrm{H}=-87.4 \mathrm{kJmol}^{-1}$

Water-gas shift reaction

(3) $\mathrm{CO}+\mathrm{H}_{2} \mathrm{O} \rightarrow \mathrm{H}_{2}+\mathrm{CO}_{2} \quad \Delta \mathrm{H}=-40.9 \mathrm{kJmol}^{-1}$

Steam reforming reaction

(4) $\mathrm{CH}_{4}+\mathrm{H}_{2} \mathrm{O} \rightarrow 3 \mathrm{H}_{2}+\mathrm{CO} \quad \Delta \mathrm{H}=206.3 \mathrm{kJmol}^{-1}$

Because $\mathrm{CO}_{2}$ and $\mathrm{CO}$ are present, there is also an important contribution of Boudouard reaction (which is the main equilibrium found in $\mathrm{CO}_{2}$ activation).

(5) $\mathrm{CO}_{2}+\mathrm{C} \rightarrow 2 \mathrm{CO}$

$\Delta \mathrm{H}=159,7 \mathrm{kJmol}^{-1}$

Changes in pressure or temperature within relatively narrow limits can produce significant shifts of the equilibrium composition towards either the starting materials or the end products [10].

Figure 3 shows the $\mathrm{H}_{2}$ molar concentration achieved in each experiment. We will focus on the experiments made with steam first. At a first glance, one can see that the $\mathrm{H}_{2}$ maintains a very stable value during all the experiments made with steam. Also, we can see that temperature seems to favour $\mathrm{H}_{2}$ production in steam gasification via the reactions (1) and (3), (see Table 2, the $\mathrm{H}_{2}$ molar fraction and the HHV attained their maximun value). Apart from that, the increasing value of $\mathrm{CO}$ as temperature rises indicates that equilibrium (1) might be predominant, and Boudouard reaction might also be present.

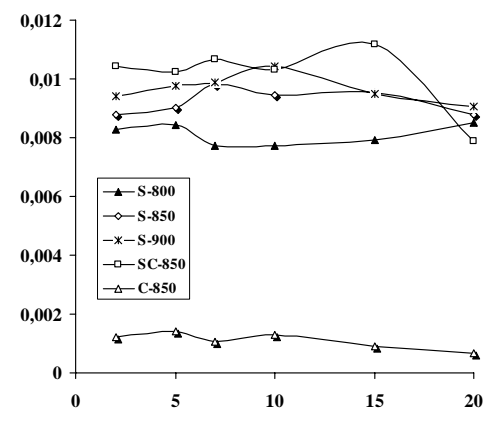

Figure 3. $\mathrm{H}_{2}$ conc. $\left(\mathrm{mol} \cdot \mathrm{NL}^{-1}\right)$ of the gas produced 
Table 2. Molar fraction, $\mathrm{H}_{2}$ production and $\mathrm{HHV}$ of the gases produced.

\begin{tabular}{|c|c|c|c|c|c|c|}
\hline & $\mathbf{H}_{2}$ & $\mathrm{CH}_{4}$ & $\mathrm{CO}$ & $\mathrm{CO}_{2}$ & $\begin{array}{l}\mathrm{g} \mathrm{H}_{2} \cdot \mathrm{kg}^{-1} \\
\text { biomass }\end{array}$ & $\begin{array}{c}\text { HHV } \\
\left(\mathrm{MJ} \mathrm{m}^{3} \mathrm{~N}^{-1}\right)\end{array}$ \\
\hline S-800 & 0,283 & 0,006 & 0,141 & 0,125 & 25,04 & 19,19 \\
\hline S-850 & 0,270 & 0,004 & 0,230 & 0,173 & 24,57 & 15,92 \\
\hline CS-850 & 0,289 & 0,007 & 0,319 & 0,201 & 14,70 & 17,47 \\
\hline C-850 & 0,026 & 0,001 & 0,533 & 0,314 & 0,54 & 19,69 \\
\hline S-900 & 0,311 & 0,003 & 0,289 & 0,112 & 36,14 & 15,36 \\
\hline Char & 0,228 & 0,074 & 0,131 & 0,213 & 18,30 & 7,523 \\
\hline
\end{tabular}

At higher temperatures not only these reactions are favoured, but also the reactant molecules diffuse faster, reaching the active sites of the char surface. This seems to be clear for the range of temperature considered (see Table 3) since the burn-off reached for each sample is related to temperature.

Table 3. Textural characteristics of the carbons produced.

\begin{tabular}{|c|c|c|c|c|c|}
\hline Sample & $\begin{array}{c}\text { Burn- } \\
\text { off } \\
(\%)\end{array}$ & $\begin{array}{c}\mathrm{S}_{\mathrm{BET}} \\
\left(\mathrm{m}^{2} \cdot \mathrm{g}^{-1}\right)\end{array}$ & 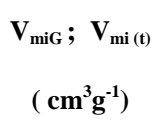 & $\begin{array}{c}V_{\mathrm{meG}} \\
\left(\begin{array}{c}\mathrm{cm}^{3} \mathrm{~g}^{-} \\
1\end{array}\right)\end{array}$ & $\begin{array}{c}S_{e x(t)} \\
\left(m^{2} g^{-1}\right)\end{array}$ \\
\hline Char & 79,2 & 43 & 0,$022 ; 0,017$ & 0,010 & 13 \\
\hline C-850-30 & 19,3 & 446 & 0,$243 ; 0,223$ & 0,021 & 56 \\
\hline S-800-30 & 46,9 & 808 & 0,$426 ; 0,307$ & 0,067 & 166 \\
\hline S-850-30 & 49,5 & 813 & 0,$427 ; 0,363$ & 0,076 & 174 \\
\hline S-900-30 & 53,4 & 437 & 0,$216 ; 0,291$ & 0,067 & 360 \\
\hline CS-850-30 & 37,1 & 674 & 0,$357 ; 0,312$ & 0,057 & 125 \\
\hline
\end{tabular}

However, the way in which the activation takes place is very different if we consider the porosity development on the chars.

According to Bessant and Walker [11], to achieve optimum activation upon carbon gasification it is important that gasification occurs essentially uniformly (in the radial direction) through the carbon particles. This occurs when the concentration of activating gas decreases little from the exterior to the center of the particle during gasification, or when the resistance to diffusion of the activating gas through the particle is small compared to the chemical resistance to gasification. This is denoted as Zone I kinetics. At the other extreme, when resistance to diffusion is very large compared to resistance to gasification, carbon removal occurs solely at the exterior of the particle (non-uniformly), and no activation of the remainder of the particle occurs. This is denoted as Zone III kinetics [12]. According to our results, for the range of temperature $800-850^{\circ} \mathrm{C}$ kinetics might be of type I (activation is uniform, increasing the values of $\mathrm{V}_{\mathrm{mi}}$ and $\mathrm{V}_{\text {me }}$, as it can be seen in Table 3). On the contrary, for the range $850-900^{\circ} \mathrm{C}$, type-III kinetics must be predominant. This must be responsible for this great rise in burn-off and $\mathrm{S}_{\mathrm{EXT}}$ (some external burning has possibly occurred too).

We can then say that an increase in temperature is good in the sense that it produces a gas with a HHV, but it does not result positive for porosity development.

Let's now analyse the effect of activating agent (experiments C-850, S-850 and CV-850). First, the $\mathrm{H}_{2}$ production of the gas generated is lower for CV-850 experiment than in the case when only steam is used. Having into account that $\mathrm{CH}_{4}$ is higher and $\mathrm{CO}$ is lower in the former case, this could be attributed to a less contribution of steam reforming reaction when both agents are used. This high $\mathrm{CH}_{4}$ concentration makes the $\mathrm{HHV}$ of this gas higher than the one of S-850 run.

With regards to $\mathrm{C}-850$ run, the $\mathrm{H}_{2}$ production is very poor as it was expected having into account that without steam feeding, the only source of $\mathrm{H}_{2}$ is the one contained in the raw material. However, the HHV of this gas is very high $\left(17.69 \mathrm{MJ} \mathrm{m}^{3} \mathrm{~N}^{-1}\right)$ due to the great amount of $\mathrm{CO}$ that is generated in this processes, via Boudouard equilibrium.

On the other hand, the porosity development of this carbon (C-850) is poor if compared to the samples $\mathrm{S}-850$ and $\mathrm{SC}-850$ in the sense that the pores volumes and $\mathrm{S}_{\mathrm{BET}}$ are lower. As some authors have stated, the way in which $\mathrm{CO}_{2}$ and steam react is very different; $\mathrm{CO}_{2}$ reacts with the active sites in the inner of the pores, producing narrow micropores on the carbons and widening them as time is increased, and steam yields pores of all the sizes from the early stages of the process (because it reacts with the active sites in the pores walls) [13]. In this sense, as the activating time employed is short, the pore size distribution found in sample $\mathrm{C}-850$ is mainly on the micropore range. This is in agreement with the fact that widening of micropores by $\mathrm{CO}_{2}$ becomes predominant from burn-off degrees close to $40-60 \%$ [13]; for C-850, a burn-off of $19,3 \%$ was attained, so this sample should be essentially microporous, as it occurs $(92 \%$ of micropores). The case of S-850 also is in agreement with this hypothesis since this carbon presented a higher mesoporous contribution (and $85 \%$ of micropores) and a higher $\mathrm{S}_{\mathrm{BET}}$ value (this agent develops porosity faster). The run made with $\mathrm{CO}_{2}$ and steam gave rise to an intermediate situation in terms of all the parameters studied $\left(\mathrm{S}_{\mathrm{BET}}, \mathrm{V}_{\mathrm{mi}} / \mathrm{V}_{\text {me }}, \mathrm{H}_{2}\right.$ production and $\left.\mathrm{HHV}\right)$ which can be interesting for many applications involving both interests (but it also implies higher operating costs).

\section{CONCLUSIONS}

The differences observed in the composition of the gas generated and the porosity development produced in the char are a function of temperature, which can be optimized in order to reach the best compromise among hydrogen production, HHV of the gas generated, the most appropriate diffusion (and avoid of external burning of the carbon) and thus the best porosity development. Here we intend to study the reactions taking place in these activation processes and to propose the 
experimental conditions which satisfy both a good porosity and an interesting gas (with high $\mathrm{HHV}$ or $\mathrm{H}_{2}$ content). The best results were achieved for the experiments carried out with steam since it gives rise to an interesting porous development and $\mathrm{H}_{2}$ concentration.

\section{ACKNOWLEDGEMENTS}

The authors would like to express their gratitude to the "Junta de Extremadura-Consejería de Educación, Ciencia y Tecnología" and the "Almaraz Nuclear Plant", for the financial support through projects 2PRO4B016 and $169 / 06$, respectively. S. Román would like to thank the "Junta de Extremadura" for the research grant received.

\section{REFERENCES}

[1] Krzysztof J. Ptasinski, Mark J. Prins, Anke Pierik. Exergetic evaluation of biomass gasification. Energy 32 (2007) 568-574

[2] A. Caglar, A. Dermibas. Hydrogen rich gas mixture from olive husk via pirolysis. Energy conversion \& management. 43 (2002) 109-117.

[3] G. Taralas, M. G. Kontominas. Pyrolysis of solid residues commencing from the olive oil food industry for potential hydrogen production. J. Anal. Appl. Pyrolysis 76 (2006) 109-116

[4] J. F. González, J. Mª Encinar, C. M. González-García, E. Sabio, A. Ramiro, J. L. Canito, J. Gañán, Preparation of activated carbons from used tyres by gasification with steam and carbon dioxide, Applied Surface Science 252 (2006) 5999-6004.

[5] S. Brunauer, P. Emmett y E. Teller. Adsorption of gases in multimolecular layers. Journal of the American Chemical Society 60 (1938) 309.

[6] F. Rodríguez-Reinoso, J. M. Martín-Martínez, C. Prado-Burguete, B. McEnaney. A Standard Adsorption isotherm for the characterization of activated carbons. The journal of Physical Chemistry, 1987, 91, 515-516.

[7] B. C. Lippens, J. H. de Boer . «Studies on pore systems in catalysis V: The t- method. Journal of catalysis, 4 (1965) 319-323.

[8] M. M. Dubinin. In Progress in Surface and Membrane Science: J. F. Danielli, M. D. Rosenberg, D. A. Cadenhrad, Eds.; Academic Press: New York, Vol. 9 (1975).

[9] Toft, A. "A comparison of integrated Biomass and Electricity Systems". Ph. D Dissertation, Aston University, Birmingham (1996).

[10] H. D. Schilling. Coal Gasification: Existing Processes \& New Developments, Ed. Graham and Totman, 1981.
[11] G. A. R. Bessant, P. L. Walker. Activation of anthracite: using carbon dioxide versus air. Carbon 32, 6 (1994) 1171-1176.

[12] P. L. Walker, F. Rusinko, L. G. Austin. Advances in cataysis 11 (1959) 133.

[13] F. Rodríguez Reinoso, M. Molina Sabio, M.T. González. The use of steam and $\mathrm{CO}_{2}$ as activating agents in the preparation of activated carbons, Carbon 33 (1995) $15-23$. 